\title{
Profitability vs. Credit Score Models-A New Approach to Short Term Credit in the UK
}

\author{
Marko Sjoblom, Alessio Castello, Gregory Gadzinski* \\ International University of Monaco, Fontvieille, Monaco \\ Email: ^ggadzinski@inseec.com
}

How to cite this paper: Sjoblom, M., Castello, A. and Gadzinski, G. (2019) Profitability vs. Credit Score Models-A New Approach to Short Term Credit in the UK. Theoretical Economics Letters, 9, 11831196.

https://doi.org/10.4236/tel.2019.94076

Received: March 8, 2019

Accepted: April 27, 2019

Published: April 30, 2019

Copyright $\odot 2019$ by author(s) and Scientific Research Publishing Inc. This work is licensed under the Creative Commons Attribution International License (CC BY 4.0).

http://creativecommons.org/licenses/by/4.0/

\begin{abstract}
The profitability lending model was initially discussed by Eisenbeis [1] who suggested that it might be possible to build a lending model that prevailed the traditional scorecard models. In this paper, we study a unique dataset from a personal loan company based in the United Kingdom, which offered overdraft-style short-term loans to individuals with low and high credit scores during the last few years. Our results conclude that credit score does not significantly impact profitability in the overdraft market. Moreover, we argue that, assuming a good understanding of low credit score individuals, a business model that grants loans to these "new" customers is as sustainable and commercially viable as lending to higher credit profile applicants.
\end{abstract}

\section{Keywords}

Financial Innovation, Profitability Model, Overdraft, Credit Scores

\section{Introduction}

An overdraft allows customers to borrow money through their Personal Current Account (PCA). There are two types of overdrafts: arranged and unarranged. An arranged overdraft limit is agreed in advance with the bank, whereas unarranged overdrafts occur when the PCA arranged limit is exceeded.

According to the Financial Conduct Authority [2], a quarter of the adult population in the United Kingdom are overdrawn to unarranged overdraft levels every year. The same source states that over half of the UK population have no access to arranged overdrafts. This lack of access results in millions of consumers seeking non-bank alternatives such as consumer credit payday loans, door to door loans, logbook loans or guarantor loans. The presence of an arranged overdraft in a customer's credit file results in an increase in their credit score. Consumers with a good credit score are more likely to be approved for mort- 
gages and automobile credit and also benefit from lower utility costs, better mobile phone contracts and even better tenancy arrangements as most landlords check a tenant's credit score during the necessary vetting process.

Liberman et al. [3] suggests that after applying for a non-standard high-cost credit, an applicant's credit score drops by an average of ten percent within twelve months, with the immediate negative effect of about five percent. For an average payday loan applicant, the decline in credit score is permanent and the customers find it practically impossible to improve their credit ratings. The study also suggests that applying or taking out a payday loan leads to more default and credit rationing by retail banks in the future. The evidence shows that payday loan borrowers largely give up their hopes for a better financial future by the self-reinforcing stigma of being poor and not attractive for mainstream lenders. The main findings of the study are supported by complementary research [2] which observes worsening credit scores amongst consumers using non-standard credit products.

This view is supported also by additional research [4] suggesting that nearly two-thirds of mortgage applications are rejected if a customer's credit file includes just one payday loan. This credit record stays in the customer's file for an entire six years. The results highlight the self-fulfilling and self-reinforcing nature of the reputation mechanism. It is self-fulfilling because taking a non-standard lender high-cost credit lowers the credit rating of a borrower, which leads to more default, which justifies the decline in the credit score in the first place.

And yet, according to Karlan and Zinman [5], sporadic access to expensive credit helps borrowers to smooth adverse expenditure shocks and improves job retention: access to a $200 \%$ interest loan significantly increases the likelihood that a borrower is still employed six to twelve months after taking a credit. These findings are also in line with Solomon et al. [6] who investigated access to consumer credit in the UK using information from 58,642 households between 2001 and 2009. The study suggests that barriers to access essential financial services and credit can inhibit both social and economic development. The issue is deemed of particular importance for the general welfare of society as the inability of households to access primary consumer credit can exacerbate economic disadvantages that may lead to social exclusion.

According to primary research by the Citizens Advice [7], incumbent banks have undertaken extensive research to better understand their customers who use payday loans and to investigate whether they can offer an equivalent product that would compete with online payday lenders. The research includes understanding the demographics of these customers, the degree to which they would be eligible for overdraft credit and, in some cases, tracking the outcomes for these customers and comparing these with customers with existing access to arranged overdrafts.

The Citizens Advice [7] study suggests that:

1) From a risk appetite and underwriting perspective, the incumbent banks 
could, in principle, provide arranged overdrafts to 10 to 40 percent of payday loan borrowers.

2) Although the opportunity is technically possible for all the incumbent banks, the study reveals that even if a commercially viable interest rate was set, reputational and brand issues prevents incumbent banks to offer such products.

3) The study concludes that the incumbent banks do not want to be associated with this market. Furthermore, due to their legacy technology, manual processes and overheads, they would find it challenging to offer these products profitably.

Indeed, industry observation allows to state that by July 2018, two of the UK's five incumbent banks had abolished unarranged overdraft charges by rejecting transactions which take a current account balance to unarranged overdraft levels.

The area of restricted access to credit is well studied [8] [9] [10] [11] and the evidence suggests that restricting access, even to expensive credit, leads to a deterioration of the overall financial condition of potentially vulnerable households. The restricted access is harming, not helping, consumers on average.

As it stands, there is a vastly growing gap in the market between arranged overdrafts and payday loans, and, if left unaddressed, the consequences could be catastrophic to the UK economy, not just for consumers and the housing market, but to society as a whole.

The mainstream lenders are predominantly relying on cut-off underwriting models, which are based on Fair-Isaac's original ideas [12] and principles designed some sixty years ago. As an example, Bell-curves in Figure 1 highlight the link between the UK's average Experian credit score (650) and the incumbent banks arranged overdraft limits. The nation is divided by the cut-off model, which is based on risk-based approach probability of default (PD). The higher the PD, the lower the chance of accessing credit.

The cut-off model states that the poorer the credit score, the higher the PD, which equals the higher likelihood of a loan decline decision. On the other hand, the stronger the credit file, the lower the PD and the higher the likelihood of approval for an overdraft credit.

The cut-off point varies from product to product and from lender to lender, however, for a high-cost short-term credit, the methodology is straightforward. The outcome of the traditional cut-off scorecard approach is binary, the computer says yes or no.

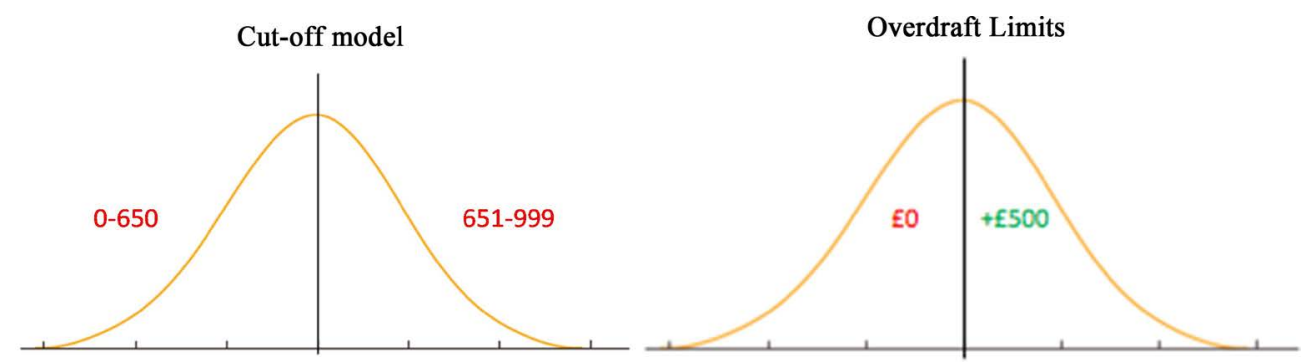

Source adapted from Payne and Raiborn [13].

Figure 1. Cut-off model and link to overdraft limits. 
In summary, the current short term lending system in the UK, based on a cut-off point in the credit score, is a non-sustainable one. This paper studies the effects of the application of a profitability model as an alternative to the credit scoring one in the UK. Thanks to a unique dataset of personal loans granted to both low and high credit score individuals, we assess to what extent the determinants and the predictability of the two groups differ from one another and if the profitability of a business model that grants loans to low credit score individuals is economically viable.

\section{Literature Review}

The aim of credit scoring systems is to estimate the $\mathrm{PD}$ of a given potential borrower prior to making the decision of extending a loan. The scores are generally established through sophisticated models based on the payment history of the borrower along with other verified information [14] that may include neural networks [15], logistic regressions [16], support vector machines [17] among others.

Minimizing default rates remains the primary focus of credit scoring based systems implemented by banks and financial experts; yet, already almost half a century ago, Eisenbeis [1] stated clearly that assessing the PD is only one of the many factors that should be considered when assessing a borrower's creditworthiness. In his seminal article, Thomas [18] theorized the necessity of changing focus from assessing the borrowers' PD to estimating their profitability since "profit scoring would allow organisations to have a tool that is more aligned to their overall objective than the present tools which estimate the risk of consumers defaulting". He states that there would be a first mover advantage in introducing profitability tools since firms doing it "will start cherry picking and going for the most profitable customers" before the market adapts to the new processes. Ever since, profit scoring studies have gained momentum in the academic world with scholars suggesting several different approaches to assess borrowers' profitability. They range from simple ex-post profitability calculations [19] [20] [21], to the estimate of the borrowing needs [22] and the probability that the applicant will take the loan based on its interest rate [23].

More recently, further contributions were made in the profitability assessment area: Serrano-Cinca and Gutiérrez-Nieto [24] propose a profit scoring system by performing non-linear multivariate regressions and by means of Chi-square Automatic Interaction Detector algorithms. Devos et al. [25] suggest a method based on the integration of the expected maximum profit measure for credit scoring that allows to select the most profitable classifier.

Lessmann et al. [17] did a comparison of 41 algorithms for both credit and profit scoring and applied them to a set of seven real-world credit scoring data sets; the main conclusion is that "advanced scoring techniques have the potential to outperform present solutions [credit scores] and logistic regression in particular in real-world settings." The authors also recommend the adoption of more automated classifiers since they produce very competitive retail scorecards 
especially in those instances in which a vast number of decisions have to be made every day and the financial consequences of an individual decision are comparably small, which is typically the case of overdrafts and payday loans.

Another financial sector that has reportedly gone beyond credit score models by adopting profitability models [26] [27] [28] [29] is the one of loans in peer-to-peer markets; in that area, lenders build profitability models by aggregating borrowers' information from social networks, endorsement, relational networks. Soft information has been used also by scholars investigating mortgage markets [30] [31] [32].

Regardless of the criteria and algorithms used to assess profitability, it is evident that several credit activities are moving beyond the linear discriminant analysis made to constitute credit scores. Verbraken et al. [33] introduce a new approach for consumer credit scoring, by tailoring a profit-based classification performance measure to credit risk modeling. Their model "is based on the Expected Maximum Profit (EMP) measure and is used to find a trade-off between the expected losses-driven by the exposure of the loan and the loss given default-and the operational income given by the loan". This approach is similar to the standard method used in determining PD, but more accurate in that it estimates the profitability of potential applicants.

Our paper contributes to the discussion about the efficiency of profitability models by presenting and analysing the results of 4369 loans granted based on the optimization of each applicants' profitability.

\section{Data and Experimental Setting}

We use a unique dataset from a company based in the United Kingdom, granting consumer loans for personal use, which offered overdraft-style short-term loans to individuals over a period of 5 years until 2018. Unsecured loans were approved on the basis of criteria further described below. The dataset consists of 4369 loans granted to new borrowers with no previous credit history with the organization. Each loan is described by 13 variables (see Table 1), such as socio-demographic descriptors (age, employment...) and an economic profile (ownership of properties, level of indebtedness...). Moreover, the institute had access to previous credit history by knowing the occurrence of past defaults with other companies, which is recorded in our database as a dummy variable. The mean loan value is 260 pounds (with a maximum of 1000 pounds), the average loan time is 23.2 days (with a maximum of 2 months), and the dataset presents an overall default rate of $28.1 \%$. Loans are provided with a constant interest rate while the amount allocated varies according to the borrowers' risk profile. The measure of profitability is the net rate of return, $R$, calculated from the total income received from the customer and the outstanding balance at the end of the outcome period. The distributions of these variables are displayed in Figure 2. The overall profitability has a mean of $4.7 \%$ with a median of $7.6 \%$. The rate of return, $\mathrm{R}$, does not follow a normal distribution but rather a binomial distribution 
Table 1. List of variables.

$\begin{array}{lc}\text { 1. Rate of Return } & \text { Profit rate } \\ \text { 2. Seniority } & \text { Job seniority (years) } \\ \text { 3. Home } & \text { Type of home ownership } \\ \text { 4. Time } & \text { Time of requested loan } \\ \text { 5. Age } & \text { Client's age } \\ \text { 6. Marital } & \text { Marital status } \\ \text { 7. Records } & \text { Existence of negative records } \\ \text { 8. Job } & \text { Type of job } \\ \text { 9. Expenses } & \text { Amount of expenses } \\ \text { 10. Income } & \text { Amount of income } \\ \text { 11. Assets } & \text { Amount of assets } \\ \text { 12. Debt } & \text { Amount of debt } \\ \text { 13. Amount } & \text { Amount requested of loan }\end{array}$
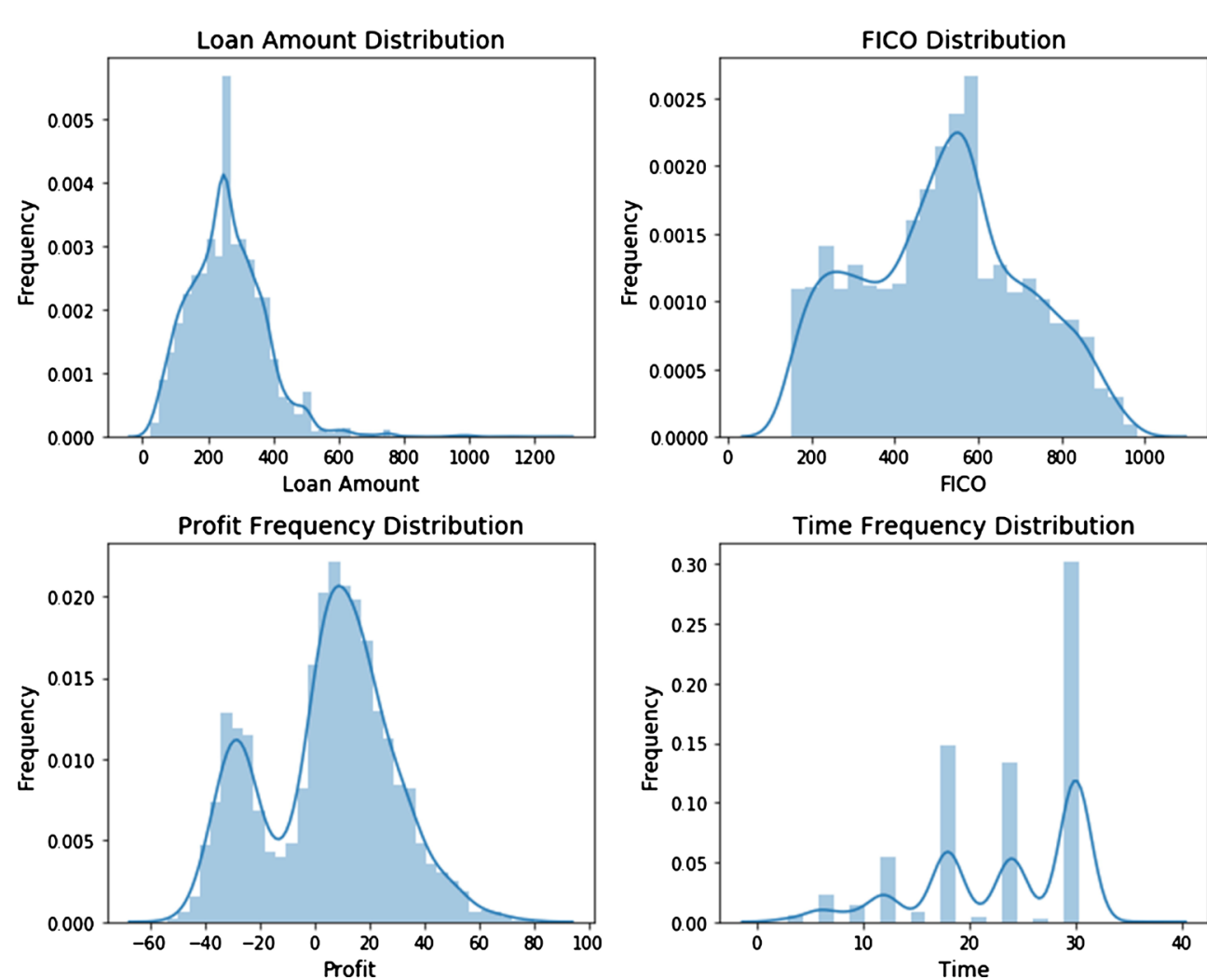

Figure 2. Histograms and kernel distributions.

with the negative skew caused by defaulted loans that were only partly recovered.

As stated above, the loans granted by the institution did not rely on cut-off underwriting models based on FICO or Experian scores. Indeed, the mean of the FICO score is 500 and the median 530, both being below the average Experian 
score measured in the UK in 2017 of 650 . To justify this choice and promote their business model, the $\mathrm{CEO}$ of the company stated the following:

"Credit decisions are made using a profitability model, which does not rely on credit reference agency data, and results in a fundamental change in the high-cost credit markets in the United Kingdom. Our profitability-model process consists of multiple steps and interfaces to third-party data providers. It starts with a data capture including but not limited to personal details and biometrics details, which are verified and confirmed through third party interfaces such as identity verification and fraud prevention purposes. Once all data is captured and verified, the profitability-model enters into the decision engine phase which firstly assesses the creditworthiness of the applicant. Following the outcome of the creditworthiness assessment, the analytical model assigns the applicant to one of the lender's profitability buckets that determines what overdraft limit is granted to the customer".

In order to assess the relationship (or lack of) between the credit score and profitability, i.e. testing the company's business model, we first study the relationship between these two variables. Figure 3 depicts a scatter plot of the two variables together with their kernel distributions.

The scatter plot depicts the relationship between the data with the following colour code: the darker the shade of blue the larger the number of points. If the observations are centered around the means, one can observe that there is no clear relationship between the two variables though. The negative and positive profit rates look randomly spread across the range of FICO scores. As a matter of fact, the Pearson correlation coefficient is equal to -0.002 with a $p$-value equal to 0.92 . Moreover, the average FICO score for positive return loans $(\mathrm{R}>0)$ is 520 compared

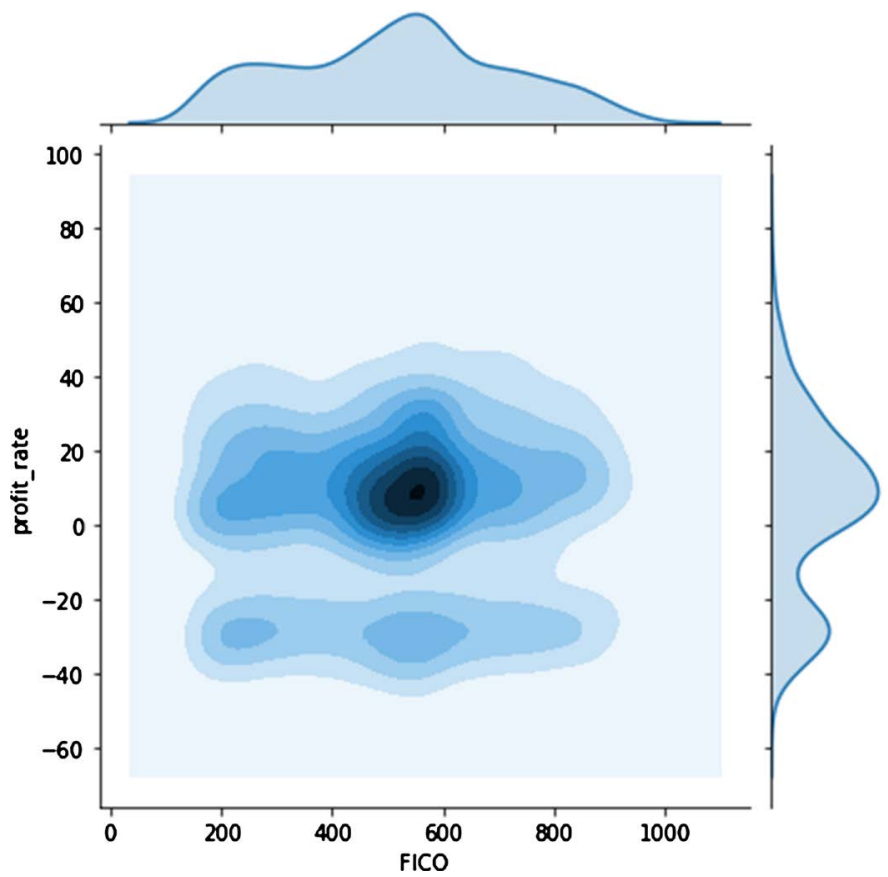

Figure 3. Rate of return and FICO score. 
to 507 for non-performing loans $(\mathrm{R} \leq 0)$, the difference being non-significant using a $\mathrm{t}$-test for the equality of means assuming different variances.

To further investigate the claim that credit score has no influence on profitability, we separate our dataset in two samples: the first sample includes the borrowers who had a score above 650 ("High CS") and the second sample those below that level ("Low CS"). As stated above, this threshold is based on the average Experian score in the UK for the year 2017. The sample rate of return of the Low CS is slightly below the High CS group, with $4.64 \%$ against $5.03 \%$ respectively, but the difference is not significant at the $5 \%$ significance level. Thus, contrary to previous results (see for instance [24]) that were based on traditional scoring data, we conclude that there is no linear relationship between credit scores and profitability in our dataset. On the opposite, it is interesting to note that the distribution of the "loan amount" is significantly different between the two sets, with High CS borrowing on average 290 pounds whilst the Low CS profiles were allowed to borrow only 240 pounds. The next step is then to determine further which factors explain the profitability measure and whether or not they differ from one sample to the other.

\section{Methodologies}

\subsection{Multiple Regression Analysis}

We run best subset regression analyses on our two samples to investigate which factors have the highest explanatory power. Unlike other studies that use logistic regression as their benchmark model for credit scoring, we have more information than a default/non default binary variable, and hence can run classical multiple regression analyses. Table 2 and Table 3 present the results of the best regression model for each sample, including both categorical and continuous variables ${ }^{1}$. The outputs are remarkably similar in terms of variation of the data explained, both adjusted R-squared being close to $60 \%$. Whilst it is difficult to judge when a R-squared is good enough, it seems that our multivariate linear regressions are not fully able to explain profitability though, and one may consider using more sophisticated techniques based on nonlinear relationships as reported by Serrano-Cinca and Gutiérrez-Nieto [24]. Having said that, several beta coefficients are statistically significant and the common set of variables explaining profitability includes among the most significant ones the loan amount, income, seniority, nature of the job, and the existence of past delinquent accounts. However some differences appear. Firstly, the number of significant variables is bigger for the Low CS individuals, including the borrower's indebtedness, and the amount of outstanding assets. This result highlights the benefit of adding new explanatory variables for low credit score individuals and suggests that a better scrutiny of the socio, and above all, economic profile of the applicant is needed in order to correctly understand and evaluate the profitability of individuals with lower credit scores. However, one knows that multiple regression

${ }^{1}$ Categorical variables are all coded as dummy variables. 
Table 2. Best multiple regression for low credit score individuals.

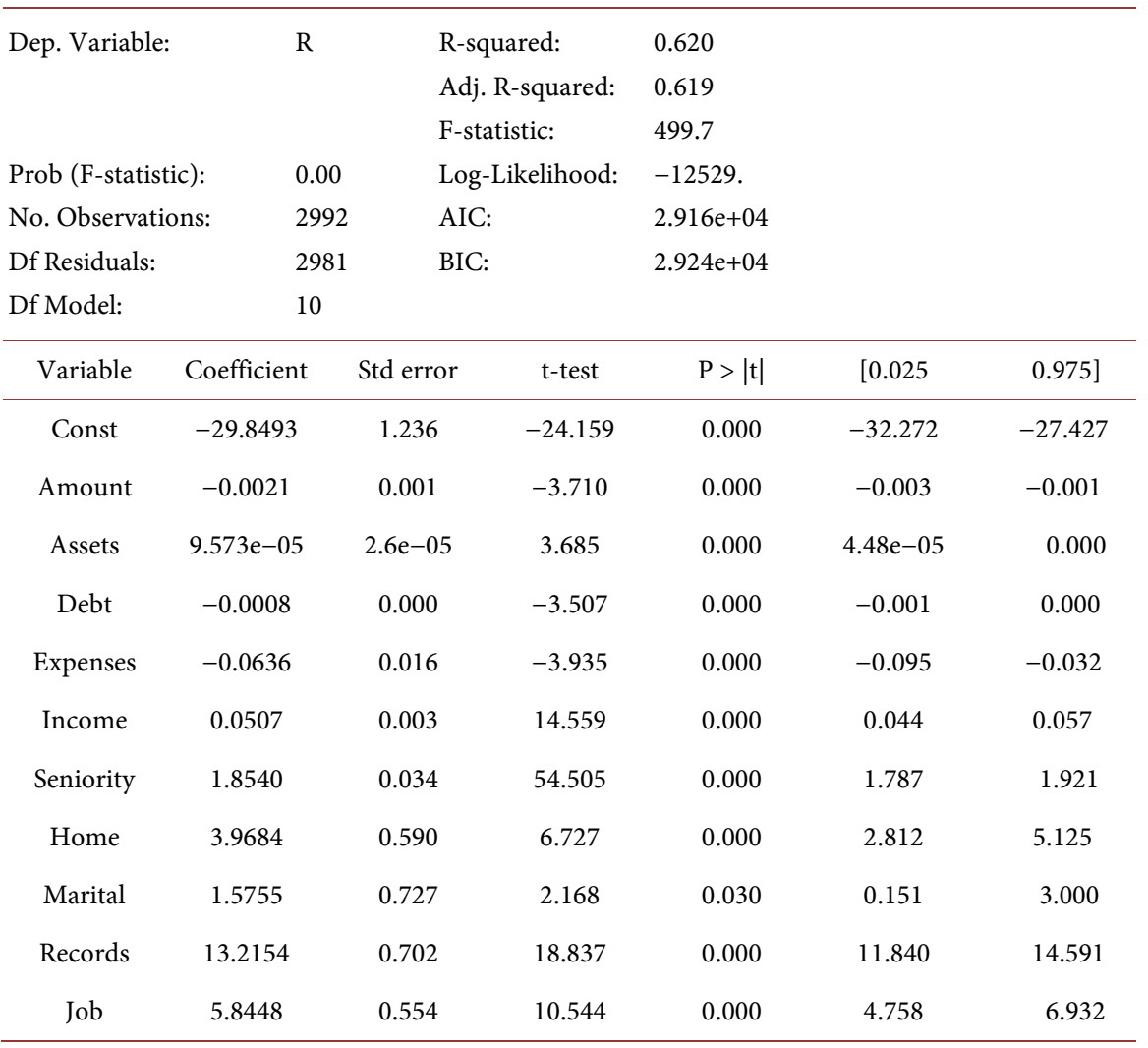

Note: Best subset regression implemented by applying a backward elimination method based on the AIC criterion.

Table 3. Best multiple regression for high credit score individuals.

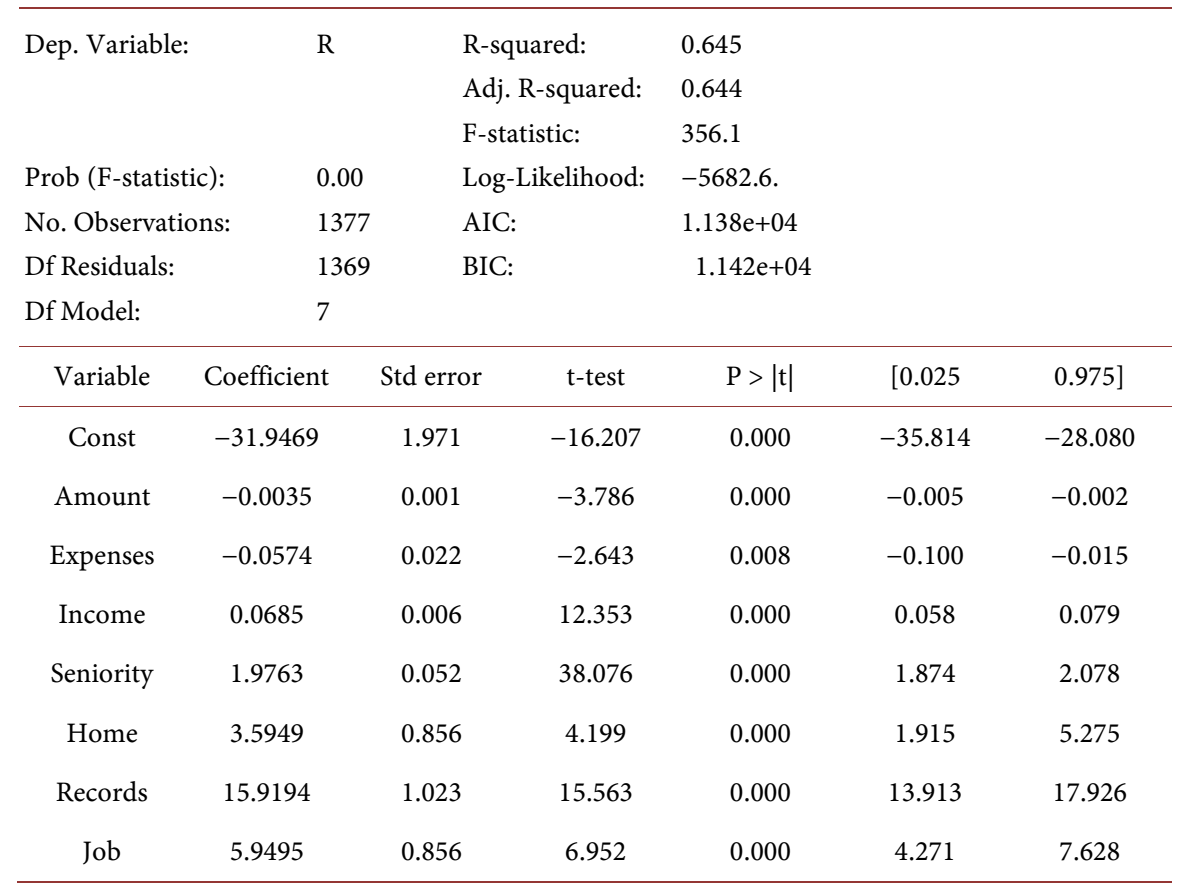

Note: Best subset regression implemented by applying a backward elimination method based on the AIC criterion. 
analyses are not necessarily synonymous of predictability, in other words, higher statistical accuracy does not equal higher profitability. To investigate further how difficult it is to separate profitable borrowers $(R>0)$ from bad ones $(R<0)$, we now implement an artificial neural network models (ANN).

\subsection{Artificial Neural Network}

Recent studies have used different variations of Artificial Neural Network (ANN) on large datasets with success (see for instance [17]). Following the literature, and since most ANN models work with binary classification, we have created a new dependent variable, a dummy variable equals to 1 if the profit rate is positive and zero otherwise. Moreover, in order to achieve better results, classical data pre-processing was carried out, including the standardization of all the independent continuous variables. Among several competing models, we have chosen to use Multi-Layer Perceptron models (MLP), which is the simplest form of neural networks, given that it remains unclear whether more complex learning models with deeper architecture perform better ${ }^{2}$ (see [17]). Moreover, as mentioned previously, the quality of the inputs is likely to be more important than the choice of a particular model. All in all, our goal was not to search for the silver bullet classifier but rather to offer a solid enough framework in order to compare the profitability potential of our two sets of individuals.

MLP involves feeding inputs into the model with given weights, which give rise to signals that are fed forward through the hidden layers and eventually produce a continuous output. Once an error function is computed, the learning is achieved by back-propagating the error through the hidden layers and changing the value of the weights between each neuron. During the optimization process, certain parameters, such as the number of hidden neurons and the number of training iterations need to be tuned. Once the model is obtained, a decision has to be made regarding the classification of any given loan applicant. That decision is made by setting a cut-off point, which transforms the continuous score into a binary output.

Both datasets were divided into two subsets: a training set (60\% of observations) for finding the optimal parameters, and an independent test set (40\% of observations), which gives the reporting results. The outcome of the classification model can be summarized in a confusion matrix where the diagonal represents the correct predictions in the testing set. To assess the quality of our optimized profitability models, we compare two different metrics: the accuracy of the predictions and the average profit rate. Several MLP models have been tested and the best model for each dataset is reported in Table 4.

Interestingly, the difference between the models, in terms of accuracy, is very small: the low CS average accuracy rate is $77.4 \%$ when the high CS equivalent stands at $76.3 \%$. While sometimes small improvements in predictive accuracy may result in large gains in profitability, it does not seem to be the case in our ${ }^{2}$ Moreover, one problem with more complex ANN models is that their black-box nature goes against Basel III regulation, which requires more transparency in the loan granting process. 
Table 4. Best MLP model for high and low CS applicants.

\begin{tabular}{cccc}
\hline Model & Accuracy (\%) & Average Profit (\%) & Percentage of granted loans (\%) \\
\hline High CS & 76.3 & 8.43 & 78.4 \\
Low CS & 77.4 & 8.38 & 75.1 \\
\hline
\end{tabular}

data. The average profit rate is $8.38 \%$ for the low credit score and $8.43 \%$ for the high credit score individuals, both higher than their respective sample averages. This last finding should not be surprising for the reader as these "best" results are mainly theoretical and would be difficult to replicate in practice. Overall, the analysis reinforces our initial view that there is no significant differences between the two samples in terms of profitability. The market for low credit score individuals could be then seen as a new opportunity for existing and incumbent lenders, and not an irresponsible act of predatory lending, which would not necessarily require a new magical recipe to discriminate between good and bad customers.

\section{Conclusions}

Is traditional credit scoring model economically efficient? One may stress that new customers with little or thin credit history, typically below the national average credit score, are usually disadvantaged by traditional models. This lack of access to basic financing results in a misallocation of resources with millions of consumers left unserved, and hundreds of millions of pounds leaving the pockets of society's poorest.

Profitability based models include more flexible modelling whereby loans are granted based on the creditworthiness and profitability of the customer profile rather than the probability of default. Overdrafts limits must be then carefully computed in order to control for the ex-ante expected higher risk of this new population

The analysis in this paper gives support to the hypothesis that borrowers with low credit scores are as profitable as those with higher credit profiles as long as lenders have carefully selected the information at their disposal and added a risk management layer with allocated loan amount limits.

In today's world, where more detailed information is known about customers and their behaviour, more and more lenders could use this information to build relevant models and make informed decisions on the basis of profitability models. A number of Fintech companies and alternative non-standard credit lenders, which operate in the short-term or near sub-prime markets, have already developed their own bespoke, alternative models. While overdraft limits computed by these models are likely to be lower for these sensitive customers, scaling the business, while controlling for operational costs, is likely to be sustainable in the long run, and not least, improve society's welfare.

\section{Conflicts of Interest}

The authors declare no conflicts of interest regarding the publication of this pa- 
per.

\section{References}

[1] Eisenbeis, R.A. (1977) Pitfalls in the Application of Discriminant Analysis in Business, Finance, and Economics. The Journal of Finance, 32, 875-900.

https://doi.org/10.2307/2326320

[2] Financial Conduct Authority (2018) High Cost Credit Review: Overdrafts.

[3] Liberman, A., Paravisini, D. and Pathania, V. (2017) High-Cost Debt and Borrower Reputation: Evidence from the UK. SSRN Electronic Journal. https://doi.org/10.2139/ssrn.2797383

[4] Financial Conduct Authority (2018) Helping Credit Card Users Repay Their Debt: A Summary of Experimental Research.

[5] Karlan, D. and Zinman, J. (2009) Observing Unobservables: Identifying Information Asymmetries with a Consumer Credit Field Experiment. Econometrica, 77, 1993-2008. https://doi.org/10.3982/ECTA5781

[6] Deku, S.Y., Kara, A. and Molyneux, P. (2016) Access to Consumer Credit in the UK. The European Journal of Finance, 22, 941-964. https://doi.org/10.1080/1351847X.2015.1019641

[7] Citizen Advice Bureau (2016) Impact Report.

[8] Zinman, J. (2010) Restricting Consumer Credit Access: Household Survey Evidence on Effects around the Oregon Rate Cap. Journal of Banking \& Finance, 34, 546-556. https://doi.org/10.1016/j.jbankfin.2009.08.024

[9] Bertrand, M. and Morse, A. (2011) Information Disclosure, Cognitive Biases, and Payday Borrowing. The Journal of Finance, 66, 1865-1893.

https://doi.org/10.1111/j.1540-6261.2011.01698.x

[10] Morgan, D.P., Strain, M.R. and Seblani, I. (2012) How Payday Credit Access Affects Overdrafts and Other Outcomes. Journal of Money, Credit and Banking, 44, 519-531. https://doi.org/10.1111/j.1538-4616.2011.00499.x

[11] Anderson, M. and Jackson, R. (2018) Evaluating Options for the Regulation of Payday Loans. Journal of Applied Business Research, 34, 131-142. https://doi.org/10.19030/jabr.v34i1.10100

[12] Mays, E. (1998) Credit Risk Modeling Design and Application. Fitzroy Dearborn, Chicago.

[13] Payne, D. and Raiborn, C. (2012) The Ethics of Payday Loan Practices. Ethics \& Behavior, 23, 117-132. https://doi.org/10.1080/10508422.2012.682881

[14] Iyer, R., Khwaja, A., Luttmer, E.F.P. and Shue, K. (2016) Screening Peers Softly: Inferring the Quality of Small Borrowers. Management Science, 62, 1533-1841. https://doi.org/10.1287/mnsc.2015.2181

[15] West, D. (2000) Neural Network Credit Scoring Models. Computers \& Operations Research, 27, 1131-1152. https://doi.org/10.1016/S0305-0548(99)00149-5

[16] Wiginton, J. (1980) A Note on the Comparison of Logit and Discriminant Models of Consumer Credit Behavior. The Journal of Financial and Quantitative Analysis, 15, 757-770. https://doi.org/10.2307/2330408

[17] Lessmann, S., Baesens, B., Seow, H.V. and Thomas, L.C. (2015) Benchmarking State-of-the-Art Classification Algorithms for Credit Scoring: An Update of Research. European Journal of Operational Research, 247, 124-136. https://doi.org/10.1016/j.ejor.2015.05.030 
[18] Thomas, L.C. (2000) A Survey of Credit and Behavioural Scoring: Forecasting Financial Risk of Lending to Consumers. International Journal of Forecasting, 16, 149-172. https://doi.org/10.1016/S0169-2070(00)00034-0

[19] Andreeva, G., Ansell, J. and Crook, J. (2007) Modelling Profitability Using Survival Combination Scores. European Journal of Operational Research, 183, 1537-1549. https://doi.org/10.1016/j.ejor.2006.10.064

[20] Finlay, S.M. (2008) Towards Profitability: A Utility Approach to the Credit Scoring Problem. Journal of the Operational Research Society, 59, 921-931. https://doi.org/10.1057/palgrave.jors.2602394

[21] Finlay, S.M. (2010) Credit Scoring for Profitability Objectives. European Journal of Operational Research, 202, 528-537. https://doi.org/10.1016/j.ejor.2009.05.025

[22] Stewart, R.T. (2011) A Profit-Based Scoring System in Consumer Credit: Making Acquisition Decisions for Credit Cards. Journal of the Operational Research Society, 62, 1719-1725. https://doi.org/10.1057/jors.2010.135

[23] So, M.L., Thomas, L.C., Seow, H.V. and Mues, C. (2014) Using a Transactor/Revolver Scorecard to Make Credit and Pricing Decisions. Decision Support Systems, 59, 143-151. https://doi.org/10.1016/j.dss.2013.11.002

[24] Serrano-Cinca, C. and Gutiérrez-Nieto, B. (2016) The Use of Profit Scoring as an Alternative to Credit Scoring Systems in Peer-to-Peer (P2P) Lending. Decision Support Systems, 89, 113-122. https://doi.org/10.1016/j.dss.2016.06.014

[25] Devos, A., Dhondt, J., Stripling, E., Baesens, B., van den Broucke, S. and Sukhatme, G. (2018) Profit Maximizing Logistic Regression Modeling for Credit Scoring. Proceedings of the 2018 IEEE Data Science Workshop (DSW), Lausanne, Switzerland, 4-6 June 2018, 125-129. https://doi.org/10.1109/DSW.2018.8439113

[26] Morse, A. (2015) Peer-to-Peer Crowdfunding: Information and the Potential for Disruption in Consumer Lending. Working Paper No. 20899.

https://doi.org/10.3386/w20899

[27] Pope, D.G. and Sydnor, J.R. (2011) What's in a Picture?: Evidence of Discrimination from Prosper.Com. Journal of Human Resources, 46, 53-92. https://doi.org/10.1353/jhr.2011.0025

[28] Ravina, E. (2012) Love and Loans: The effect of Beauty and Personal Characteristics in Credit Markets. Working Paper, Columbia Business School, New York.

[29] Lin, M.F., Viswanathan, S. and Prabhala, N.R. (2013) Judging Borrowers by the Company They Keep: Friendship Networks and Information Asymmetry in online Peer-to-Peer Lending. Management Science, 59, 17-35. https://doi.org/10.1287/mnsc. 1120.1560

[30] Agarwal, S., Ambrose, B., Chomsisengphet, S. and Liu, C. (2011) The Role of Soft Information in a Dynamic Contract Setting: Evidence from the Home Equity Credit Market. Journal of Money, Credit and Banking, 43, 633-655. https://doi.org/10.1111/j.1538-4616.2011.00390.x

[31] Keys, B.J., Mukherjee, T., Seru, A. and Vig, V. (2010) Did Securization Lead to lax Screening? Evidence from Subprime Loans. Quarterly Journal of Economics, 125, 307-362. https://doi.org/10.1162/qjec.2010.125.1.307

[32] Jiang, W., Nelson, A. and Vytlacil, E. (2014) Liar's Loan? Effects of Origination Channel and Information Falsification on Mortgage Deluquency. Review of Economics and Statistics, 96, 1-18. https://doi.org/10.1162/REST_a_00387

[33] Verbraken, T., Bravo, C., Weber, R. and Baesens, B. (2014) Development and Ap- 
plication of Consumer Credit Scoring Models Using Profit-Based Classification Measures. European Journal of Operational Research, 238, 505-513.

https://doi.org/10.1016/j.ejor.2014.04.001 